\title{
The Effect of Covid-19 Pandemic on the Maritime Industry and the Role of the Ship Registries
}

\author{
Panagiotis Saviolakis ${ }^{1 *}$, Michalis Pazarzis ${ }^{2}$ \\ ${ }^{1}$ Ph.D Candidate, Department of Maritime Studies, University of Piraeus, Piraeus, Greece \\ ${ }^{2}$ Emeritus Professor,Department of Maritime Studies, University of Piraeus, Piraeus, Greece
}

\section{Abstract}

Objectives: The current paper focuses on the impact of the unexpected event of the Covid-19 pandemic on the maritime industry. It searches the role adopted by key stakeholders of the shipping community with particular emphasis on the Ship Registries. Methods/Analysis: In order to conduct the research, there has been a thorough investigation concerning the initiatives taken by both governmental and private sector entities. Regulations and announcements issued to handle the Covid-19 pandemic are analysed and properly assessed. Findings: The response of the shipping sector, including the Ship Registries, was decisive and covered numerous aspects of maritime activity. Some of these actions taken can only be regarded as a temporary reply of the maritime industry to the threats imposed by the disease. At the same time, a significant part of these initiatives have a more permanent character and their acceptance by the maritime industry underlines their future potential. In this case, the appearance of the random event of the Covid-19 disease acted as a catalyst for developments in the shipping sector. Novelty/Improvement: This study is expected to contribute to the scientific orientation concerning the reaction towards the impact of future unexpected events with particular emphasis on the role of the Ship Registries.

\section{Keywords:}

Covid-19;

IMO 2020;

Ship Surveys:

Mortgage;

Ship Registry.

\section{Article History}

Received: $\quad 04 \quad$ April 2021

Revised: $\quad 29$ June 2021

Accepted: 05 July 2021

Published: 14 July 2021

\section{1- Introduction}

Unexpected events have traditionally affected aspects of maritime activity. Nevertheless, after the successful termination of previous temporary crises, in some cases, their consequences ceased to exist, while in other cases their impact on the maritime industry remained and acted as a catalyst for developments. At this point, the outbreak of the Covid-19 pandemic caused numerous reactions by the stakeholders of the maritime community [1-2] including the Ship Registries [3] and the port States [4]. Measures were taken to facilitate the smooth continuation of the maritime activities, despite the regional lock-outs and restrictions in the movement of humans and material in most places around the globe.

Ship Registries are at the forefront of the actions that aim to ease the negative impact of the Covid-19 pandemic [5]. Their initiatives cover a wide range of topics such as the implementation of the new environmentally-friendly regulations regarding the fuel oil sulfur content limit, the impact on conditions of work of the maritime workers and their education/certification, the execution of ship surveys and the validity of their certificates. Furthermore, other aspects of the daily activities of the Ship Registries such as the registration of vessels, mortgages and notarization of documents are areas of concern. While some of these measures have a temporary character, others respond to both the consequences of the Covid-19 pandemic and the continuous trend towards modernization. It is this category of solutions that is expected

*CONTACT: Psaviolakis@unipi.gr

DOI: http://dx.doi.org/10.28991/esj-2021-SPER-06

(C) 2021 by the authors. Licensee ESJ, Italy. This is an open access article under the terms and conditions of the Creative Commons Attribution (CC-BY) license (https://creativecommons.org/licenses/by/4.0/). 
to remain and act as a catalyst for developments for the maritime industry. For all types of measures, the use of electronic means and other methods of remote business practice is widely used.

The necessity of the current research lies in the need to evaluate the impact of the Covid-19 pandemic in various aspects of maritime-related activities. Both public and private sector stakeholders have reacted to the challenges posed by the pandemic in numerous ways. The main target of this essay is to focus on the changes that took place in the area of the trend towards more environmentally-friendly maritime activities. In particular, the implementation of the IMO $20200.50 \%$ fuel oil sulfur content limit provides for concrete steps that will facilitate the achievement of the quantitative goals concerning the environmental impact of the shipping sector. The installation of scrubbers in vessels along with the electrification of the port facilities are among the initiatives under revision, due to the effect of the Covid-19 pandemic. Similarly, the maritime labour market is particularly affected, because of the difficulties that have appeared in the flawless movement of employees between the vessels and their country of permanent residence. The area of maritime education, including the seafarers' certification [6], is one of the sectors mostly influenced by the appearance of the Covid-19 pandemic. Either remote or online educational methods have greatly evolved and tend to dominate the market. The field of ship surveys has experienced significant changes as a means of response to the Covid-19 pandemic. There have been adjustments concerning the geographical area where the ship surveys are planned to be realised and in many cases, ship surveys have been postponed of held remotely. The duration of ship's certificates in many cases has been extended too. Similar is the case of the tax liabilities, where some Ship Registries have shown flexibility in the rescheduling of the payments. Another area that has experienced the significant impact of the Covid-19 pandemic is the procedure of the mortgage and property title registration and the registration of vessels. In this case, the consequences tend to obtain long-term characteristics, whilst in the freight market, the impact is expected to be short-lived as happened with previous extraordinary events in the past decades.

This essay contributes to the innovation in business and maritime studies since it focuses mainly on the role of the Ship Registries in the volatile environment following the outbreak of the Covid-19 pandemic. Ship Registries have acted either preemptively to respond to the needs of the maritime community, such as in the postponement of the tax liabilities, or simply complied with the various regulations imposed by the national authorities [7] and inter-governmental organizations [8]. In either case, the level and speed of adaptation to the new conditions vary significantly among the Ship Registries under examination.

The necessity of doing this piece of research - critical analysis gap - lies in the fact that it specializes in the contribution of the Ship Registries towards the successful response to the Covid-19 pandemic. While the impact of the pandemic is adequately analysed by the academic community, it is the role played by the Ship Registries' Authorities that needs further assessment. When focusing to the Ship Registries' policies, there are areas of concern, such as the implementation of ship surveys, where the community of the Ship Registries has responded satisfactorily. On the other hand, one of the major difficulties and challenges was to define the impact on the Ship Registries in less well-known areas such as the impact to the freight market, the economic policy of the Ship Registries and the trend towards digitalization of this sector.

\section{2- Materials and Methods}

The methodology followed in the current essay is based on the extraction of primary data directly from the entities that are in a position to produce regulations and other forms of compulsory legislation. Furthermore, secondary data are gathered and codified originating from the academic and scientific research that has already been conducted in this area stricto sensu as well as in other related areas of interest. These data are then combined and synthesized to reach the conclusions that represent the contribution of this research initiative to science.
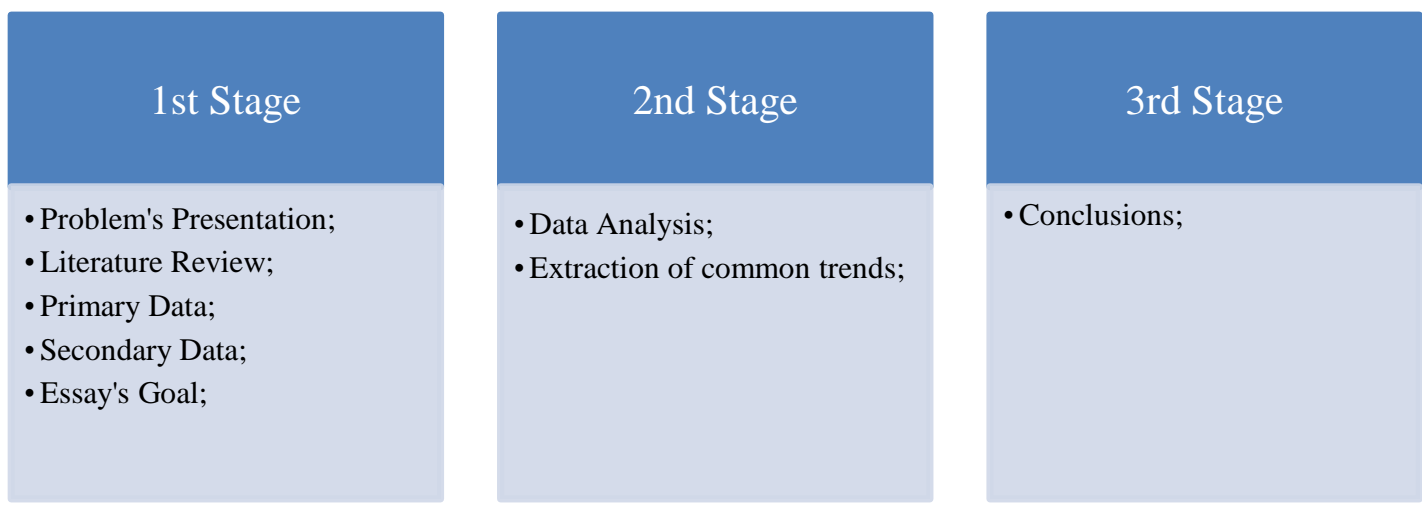

Figure 1. Flowchart of the research methodology. 


\section{3- Implementation of the IMO $20200.50 \%$ Fuel Oil Sulfur Content Limit}

Since 1st January 2020, the International Maritime Organization (IMO) has put into force the IMO 2020 regulation according to which the sulfur content of the fuel oil in vessels cannot exceed 0,5\% until 2050, except for the designated Emission Control Areas where the limit is set to $0,1 \%$ [9]. The majority of the maritime companies have chosen to use marine fuel oil of low sulfur content instead of proceeding to the necessary adjustments in the equipment onboard their vessels [10]. The environmental impact of the Covid-19 pandemic was crucial, since the contraction of the global carbon dioxide (CO2) emissions in 2020 well below 35 billion tons was the greatest reduction in just one year in history [11].

The option of installing the necessary equipment (scrubbers) is threatened by the Covid-19 pandemic, since shipyards in China and elsewhere, appointed with the task to retrofit new sulfur-trapping exhausts, are troubled by shortcomings of the supply chain and hence face difficulties in performing their contractual obligations [12]. These shipyards either face difficulties with the movement of the workforce or cannot receive the necessary machinery and raw materials to conclude their works. In this way, it is reasonable to expect that soon the target of $0,5 \%$ fuel oil sulfur content is going to be accomplished mainly due to the shift to other types of marine fuel oil as opposed to the use of scrubbers. Naturally, as circumstances gradually reach normality in the future, the contribution of scrubbers in the achievement of this goal is expected to grow.

In this area States, especially the ones with established shipbuilding industry are expected to contribute to the modernization of the current shipbuilding installations to meet the growing demand for zero-emission vessels. Forms of State-originating initiatives, such as subsidies and guarantees, are expected to materialize focusing either on the survival of the existing shipyards, or are retooling to meet the future need for reduced maritime emissions.

Closely connected to developments in the shipbuilding industry, is the evolution of the port industry. Greener shipping raises the question of lowering the environmental impact of all the chain links including both private sector and government vessels [13]. Consequently, it is expected that opportunities might arise concerning the electrification of port facilities that will lead to the decarbonizing of the port industry.

Correspondingly, Ship Registries are expected to adapt to the trend towards lower shipping emissions. This can be achieved either by encouraging the use of environmentally friendlier maritime fuel oil, or by gradually introducing new technologies that allow for the use of entirely other types of fuels such as electricity and hydrogen.

The lack of appropriate low-sulfur fuel oil in special geographic areas has led some Ship Registries to examine the exact circumstances on a case-by-case basis and consequently take no control actions in case of proper justification on behalf of the shipowner [14]. This means that if despite all efforts of the maritime company, it is impossible to source appropriate fuel oil to the vessel, then the Flag Authorities can waive the obligation for the exclusive use of low-sulfur fuel oil for certain voyages.

\section{4- Impact on Maritime Workers}

The disruption of transportation has resulted in difficulties in the change of shifts concerning the marine workers. The employment contracts have been extended, until a replacement for the seafarers can reach the ships. This is caused by restrictions [15] that have been imposed on the use of means of transportation such as airplanes and trains [16], including the quarantine [17]. Additionally, movements inside the port areas can be denied to the seafarers that have managed to reach the port of call of the ship they are planned to join. That measure was taken by many States, in order to restrict the transmission of the infection [18]. Other restrictions affected the leave of the existing crew from the vessel with the fear of contaminating the local population of the areas nearby the port installations [19]. Furthermore, vessels face obstacles while trying to perform their trade and consequently reach a port of call that will facilitate the change of crew. Additionally, in specific geographical areas, such as in the Asia-Pacific, national authorities have stepped in almost total restriction of the approach of cruise vessels, thus causing problems in the smooth movement of crew in and out of the ships. Due to the above-mentioned situation, it has been reported that in many cases the shipowners have refused to pay the seafarers' strand benefits [20].

Stranding of seafarers is inevitable and it can only be eased by the relaxation of measures regarding the movement of people and ships. Hopefully, it is expected that these are only temporary disruptions to the normal activities of the shipping industry. As long as humanity creates adequate mechanisms [21] to compete against the Covid-19 pandemic, it is expected that these phenomena will cease to exist.

A particular category of workers that use the services of short-sea shipping companies is haulage drivers. The transportation of merchandise in some cases demands the combination of both road and short-sea means of transportation. Thus, it is necessary for the vessels that operate in short-sea shipping to offer adequate room for the appropriate distancing [22]. The situation is more burdensome in the case of longer routes, where overnight accommodation has to be provided to meet the quarantine requirements. 


\section{5- Developments in Maritime Education and Certification}

The appearance of the pandemic caused significant interruption of face-to-face lessons in the educational courses of all academic fields, including maritime education. The need to protect public health resulted to the suspension of the classical teaching methods that implied the physical appearance of persons either professors or students. The need to respond to this new reality posed a tremendous challenge for the educational institutions, even though in the past several e-learning and distant-learning programs were already on offer by the academic community [23]. This time, the magnitude of the Covid-19 pandemic and the urgency of the transition to new teaching methods forced the educational institutions to quickly and decisively respond to the new circumstances.

The curricula had to be reorganized in numerous fields in order to continue to operate both in the didactic and the evaluation areas. Among the most necessary technological tools that are needed for online educational programs is the reliable internet connection. Furthermore, the existence of an internet connection has to be accompanied by fast speed to support the appropriate software. Subsequently, hardware tools, such as computers, laptops, tablets and mobile phones, are needed for the realization of learning programs. The absence of teaching material on paper has encouraged the extended use of digital means. Especially, computers and laptops are highly appreciated for their hardware performance and support of software solutions [24].

Apart from the adequate hardware resources, online learning demands software programs that can substitute the traditional methods of teaching. Modern digital technology has enabled the use of either sophisticated synchronous or asynchronous platforms such as Zoom, MS Teems, Cisco Teems, Google Meets as well as other communication platforms of wider use such as Whatsapp and Facebook messengers. The former were offered by the educational institutions while the latter is of common use by consumers around the globe. Videoconferencing is one of the features most appreciated by the users of all kinds of online platforms.

In many educational institutions, the existence of online and distant curricula before the appearance of the Covid-19 pandemic had already set the basis in terms of procedures and infrastructure for the massive initiation of learning programs in other educational areas, including the maritime courses. The great difference that occurred with the outbreak of the disease was the need for empowerment of the support and guidance during the didactic activities by the IT departments. Support groups comprising of IT experts, as well as specially trained professors, offer their guidance in order to successfully fulfill the demands of the online education environment.

Another area affected by the Covid-19 pandemic is the procedure of the seafarers' certification. In order to facilitate social decongestion, Ship Registries have established electronics functions that assist maritime workers while applying for credentials [25]. These types of remote services include methods of online assessment examinations that lead to certain certificates. It should be kept in mind that all stages of the above-mentioned process can be entirely executed electronically. This means that both the application, submission of required documentation, any necessary examination, issuing of credentials and payment are performed remotely [26].

New learning opportunities in almost all academic fields, including the maritime sector, are available to students. The wide use of either online or distant learning opportunities for maritime students is a reliable alternative to classical methods of teaching. It is expected that a great part of the current stream of online and distant learning will continue to dominate the scientific field of maritime education, given the wide use of internet connection and the abundance of the necessary hardware and software solutions that are available nowadays. The specific circumstances of maritime work with the continuous change of local time, working shifts and ship hours usually different from the educational institution's working hours are ideal for the preferential use of online and distant learning by the maritime workers [27].

\section{6- Implementation of Ship Surveys - Extension of the duration of Certificates}

Another important issue that arose from the outbreak of the Covid-19 pandemic is the validity of the various maritime Certificates. Numerous Certificates are issued by the Ship Registries services that need periodical renewal. In many cases, the renewal of these Certificates has as a condition the realization of onboard inspection or require for additional assessment by the administration of the Flag State.

These Certificates contain the Standards of Training, Certification and Watchkeeping (STCW), SOLAS 74, MARPOL 73/78, ISPS, ISM as well as other Certificates of Ship Registry and Maritime Labour Convention (MLS 2006). The duration of these Certificates in most cases has been extended by the respective Ship Registry's Authorities to overcome the inability to actually perform the necessary controls. The administrations of many Ship Registries, such as Marshall Island which is one of the three biggest Ship Registries in the world, allow for a three months extension of these certificates [28].

Similar is the case of the inspections that are connected with the dry-docking and ship repairs. Apart from the disruption of the normal operations of the shipyard itself, there are difficulties with the adequate supply of equipment and spares for the vessels that intend to perform ship repairs. For example, these ship repairs might refer to the Ballast 
Water Management Systems (BWMS). Again, with the cooperation of the appropriate Classification Society, the certificates are kept valid with the combination of short-term extension [29] and the use of remote surveys [30]. In the case of extreme extenuating circumstances, the extension period may go beyond the three months [31], provided that the vessel performance is not regarded as substandard [32].

Although temporary extensions of the validity of certificates are not something new to the maritime industry, the trend of remote inspections, due to the Covid-19 pandemic, is a new feature [33]. It can be estimated that remote inspections, especially in isolated areas not easily accessible by the representatives of the Flag State of the Recognized Organisation (RO), are pretty alluring for both the vessels and the inspectors.

Additionally, maritime surveys are encouraged to take place in geographic areas less affected by the Covid-19 pandemic. In order to preserve the health of the personnel involved and to be able to perform any necessary extraordinary ship repairs, the operators of the vessels are advised to schedule inspections of their vessels in selected areas that are not severely affected by the pandemic. In this way, the movement of people [34], such as the inspectors, and the transportation of the appropriate equipment can be facilitated with minimal disturbance by the national and regional restrictions of the area [35] where the port of inspection is located [36]. As the spread of the disease is very unpredictable and the local regulations tend to alter following the recent developments in the field of the disease, it is understood that this practice can only marginally influence in the long term the attitude of the maritime industry towards the pandemic.

Inspections and audits of vessels are further eased by the initiation of Detention Prevention Programs (DPP) by the Authorities of the Flag Administration. The adoption of a DPP resonated through the necessity of the maritime industry to successfully respond to the challenge of the Port State Control (PSC). By this means the ship operator with the collaboration of the Ship Registry can evaluate the possibility of ship survey in the forthcoming port of call by taking into consideration various contributing factors such as the performance of the Flag and the Classification Society in previous inspections and the overall condition of the vessel [37]. Although all the ports that participate in the same Memorandum of Understanding (MoU) share a common set of rules and regulations, there is still room for the application of special rules in each port separately. This increases the PSC boarding risk and the possibility of detention. The response on behalf of the community of the Ship Registries was the creation of a PSC risk assessment system that prepares both the maritime company and the Flag Authorities against the possibility of a PSC ship inspection in the next port of call. The roots of such systems date before the outbreak of the Covid-19 disease, but the mounting difficulties concerning the ship inspections due to the pandemic are better dealt with the use of DPP's and their importance is expected to remain even after the successful handling of the pandemic.

\section{7- Extension of Payment of Tax Liabilities}

Numerous Ship Registries have initiated special measures to ease the burden of the obligations to the maritime companies. Either financial difficulties on behalf of the companies or the technical obstacles that do not permit the planned payment of obligations have encouraged Ship Registries to adopt more flexible tax collecting policies. More specifically, the payment of the Annual Fee and the Tonnage Tax in some cases has been extended for a short period of two months.

Measures that aim to assist the maritime companies in the fulfillment of their obligations are expected to apply, whenever any extraordinary circumstances destabilize the shipping industry. The Covid-19 pandemic is such a case and special arrangements regarding the extension of the payment of tax liabilities are expected to withdraw as soon as normality returns to the maritime market.

\section{8- Electronic / Remote Registration of Mortgages and Property Titles - Notarization - Registration and Closing of Registration of Vessels}

The smooth operation of the shipping sector demands the appropriate registration of the ship mortgages and the property titles. Many Ship Registries, realizing this necessity, have established efficient processes and ensure the continuity of the maritime operations. In particular, the maritime companies no longer need to physically contact the Ship Registries Authorities, to register ship mortgages or other property titles, since they have the option to perform such tasks electronically. This electronic service is of great importance, especially for the banking sector, in order to safely continue to provide shipping finance.

Apart from the electronic transfer of property titles and mortgages, Ship Registries offer a wide variety of complimentary services that are necessary for the ordinary activities of the shipping sector. This kind of function includes the notary services that are appropriate for the registration of shipping liens, property rights as well as other types of documents where acknowledgment is needed. It should be kept in mind that this kind of notary service might be offered remotely and not necessarily by electronic means. The use of electronic means includes the use of video calls for the verification of the signatories' identity and the exchanger of electronic documents. The use of electronic means is further facilitated by the adoption of electronic signatures [38]. 
In some cases, the Flag Administration's Authorities might show significant flexibility by not requiring the submission of certain documents. This means that instead of setting particular requirements, there might be a waiver of these requirements in its discretion by invoking its authority [39].

Apart from the mortgages the registration and the closing of the registration of the vessel in a Ship Registry has seen significant changes due to the appearance of the Covid-19 pandemic. The long-lasting need for the streamline of the registration, including the Parallel/Bareboat Charter Registration [41], of vessels has to lead several Ship Registries in the acceptance of electronic means for the majority of the documentation needed for the registration, re-registration and closing of registration of a vessel. In this way, electronic applications along with the digital versions of original documents are widely accepted and the whole vetting procedure is executed electronically. Another innovation is the abolition, at least in the early stages, of the need to submit documents from the Classification Societies, since all these documents are derived directly through automated channels of exchange between the Ship Registries and the Recognized Organizations (RO). Although these measures are a solution to the threats posed by the pandemic, it is expected that they will remain even after the end of this crisis, since they satisfy the continuous need of the maritime community for simpler and faster solutions.

Electronic recordation is part of the wider and continuous trend towards faster, agile and more efficient transactions that replace traditional functions in all facets of business activities. In this way, the mortgages, instruments and other documents including notary services are expected to incorporate the use of modern technological solutions permanently even after the mitigation of the effects of the Covid-19 pandemic. On the other hand, the waiver of some documents and requirements is expected to cease to exist, when the shipping sector operation returns to normality.

\section{9- Effects on the Freight Market}

The effect of the Covid-19 pandemic on the freight market is significant since there has been a collapse of both the dry and the tanker market segments of 73 and 33\% respectively [41], while the Baltic Dry Index (BDI) fell 89,1\% on between September 2019 and May 2020. The lower drop in the tanker market is attributed to the higher demand for tankers for floating oil storage due to the lower consumption and the consequent surplus of oil [42]. This is particularly evident in the crude oil sub-sector since crude oil can easily be stored. It is not unfamiliar for the shipping sector to suffer the consequences of an exogenous event such as the Covid-19 pandemic, as the oil crises of the past have shown. Maritime companies' cash flows have faced the turbulences of the freight markets in the past and in almost all cases they managed to recover.

The strong relationship between the Covid-19 pandemic and the fluctuations of the freight market lies primarily in the prohibition of the transportation of people and goods throughout the globe. Additionally, there are secondary effects from the decline of the price of oil that is of vital importance for the movement of vessels and additionally itself is one of the main transported cargoes. The impact of the stock markets should not be neglected too, as they offer a third-round effect to the freight market.

The inherent volatility of the freight market to the exogenous events such as the Covid-19 pandemic and its successful reaction to past threats, such as the oil crises and the adoption of the low-sulfur maritime emissions regulation, leads to the result that any consequences to the freight market will be absorbed during the gradual restart of the economic activities.

\section{0- Conclusions}

Developments in the shipping industry often have occurred due to unexpected events either caused by human actions or by the power of nature. One such phenomenon has struck the maritime sector along with the rest of the economy due to the Covid-19 pandemic. The effects to the shipping industry are numerous and cover a wide range of areas with economic, social and environmental impacts. Ship Registries, as the main stakeholder of the sector, have responded to this challenge in various ways to counterbalance the adverse consequences of the pandemic. Some of these measures are totally new to the industry while other measures are part of an already established pace for the modernization of the maritime industry in the digital era. At the same time after the end of the pandemic and the return to normal life, a number of these initiatives on behalf of the Flag Administrations are expected to remain as part of the greater effort towards the industry's adaption to the ever-changing business environment.

In this way, it should be kept in mind that part of the measures taken by the Ship Registries is expected to be withdrawn. These measures include the relative flexibility in the scheduled payment of financial obligations of the shipping companies such as the tonnage tax. Other measures that possess a temporary character involve the waiver that is granted by the Authorities of the Flag in case of the vessel's proved inability to use low-sulfur fuel oil in order to meet the IMO obligation concerning the shipping fuels emissions.

On the other hand, the majority of initiatives targeting the Covid-19 pandemic resonates through the general trend towards the modernization of the maritime industry. These are measures that were to be adopted anyway regardless of 
the appearance of the pandemic. It was simply of catalyst for developments that accelerated the adoption of new attitudes and technics. Measures of this category include the widespread of e-learning and distant learning methods in maritime education for both shore-based personnel and crew members. Furthermore, the speed, convenience and reliability of the registration of a mortgage and other proprietary titles through electronic means are hard to compete with by the traditional old-style procedures. Again the electronic transfer of documents and the electronic recordation is expected to prevail in the field of the notarization services on offer by the Ship Registries. In the area of ship surveys, the establishment of remote surveys for the vessels is a function that is expected to facilitate the maritime industry even after the end of the Covid-19 pandemic. Its efficiency and control of costs are highly valued by both the Ship Registries Authorities and the shipping companies.

\section{1- Declarations}

\section{1-1- Author Contributions}

Conceptualization, P.S. and M.P.; methodology, P.S. and M.P.; writing—original draft preparation, P.S. and M.P.; writing - review and editing, P.S. and M.P. All authors have read and agreed to the published version of the manuscript.

\section{1-2- Data Availability Statement}

The data presented in this study are available on request from the corresponding author.

\section{1-3- Funding}

The authors received no financial support for the research, authorship, and/or publication of this article.

\section{1-4- Conflicts of Interest}

The authors declare that there is no conflict of interests regarding the publication of this manuscript. In addition, the ethical issues, including plagiarism, informed consent, misconduct, data fabrication and/or falsification, double publication and/or submission, and redundancies have been completely observed by the authors.

\section{2- References}

[1] EMSA (European Maritime Safety Agency). Available online: http://www.emsa.europa.eu/newsroom/covid19-impact/item/ 4435-june-2021-covid-19-impact-on-shipping-report.html (accessed on March 2021).

[2] UNCTAD (United Nations Conference on Trade and Development). Available online: https://unctad.org/system/files/officialdocument/dtltlb2021d1_en.pdf (accessed on March 2021).

[3] Hellenic Shipping News Worldwide. Available online: https://www.hellenicshippingnews.com/republic-of-the-marshall-islandsurges-countries-to-treat-seafarers-as-key-transport-workers/ (accessed on March 2021).

[4] Relief Web - OCHA (United Nations Office for the Coordination of the Humanitarian Affairs). Available online: https://reliefweb.int/sites/reliefweb.int/files/resources/pacific_logistics_cluster_shipping_operations_update_200915.pdf (accessed on March 2021).

[5] Yazir, Devran, Bekir Şahin, Tsz Leung Yip, and Po-Hsing Tseng. "Effects of COVID-19 on Maritime Industry: a Review." International Maritime Health 71, no. 4 (December 30, 2020): 253-264. doi:10.5603/imh.2020.0044.

[6] Class NK. Available online: https://www.classnk.or.jp/hp/en/activities/covid-19/\#t4 (accessed on February 2021).

[7] International Maritime Organization (IMO). Available online: https://wwwcdn.imo.org/localresources/en/MediaCentre/ HotTopics/Documents/covid\%20overviews\%20tables/Notifications\%20related\%20to\%20COVID-19\%20received\%20from\% 20member\%20states.pdf (accessed on March 2021).

[8] Paris MoU. Available online: https://www.parismou.org/paris-mou-guidance-regarding-impact-covid-19 (accessed on May 2021).

[9] Werner, Michael Jürgen, Julia Kampouridi, and Caio Prado Rocha. "A Global Sulphur Emissions Cap and a Carriage Ban to Match: Considerations on the IMO 2020 Prohibition on the Carriage of Non-Compliant Fuel Oi." Zeitschrift Für Europarechtliche Studien 23, no. 1 (2020): 77-102. doi:10.5771/1435-439x-2020-1-77.

[10] Mohamed, Hairul Azmi Bin, and Aminuddin Md Arof. "Impact of Sulfur Cap 2020 regulation on the shipping industry.” Marine frontier@UniKL 11,no. 2 (2020): 42-50.

[11] United Nations Economic and Social Commission for Asia and the Pacific (ESCAP). Available online: https://www.unescap.org/sites/default/d8files/knowledge-products/ShippingPoliyBrief-16Oct2020-FINAL.pdf (accessed on February 2021). 
[12] Oyenuga, Adekola. "Perspectives on the Impact of the COVID-19 Pandemic on the Global and African Maritime Transport Sectors, and the Potential Implications for Africa's Maritime Governance.” WMU Journal of Maritime Affairs 20, no. 2 (April 6, 2021): 215-245. doi:10.1007/s13437-021-00233-3.

[13] Samiotis, G., D. Grekos, and P. Saviolakis. "Legal Analysis of Government Ships' Immunity in the Light of Sustainable Development and Environmental Security." Environmental Policy and Law 50, no. 4-5 (March 12, 2021): $325-338$. doi:10.3233/epl-200234.

[14] World Economic Forum. Available online: https://www.weforum.org/agenda/2020/05/how-to-build-a-bluer-ocean-economyafter-cobid-19 (accessed on April 2021).

[15] Republic of the Marshall Islands Maritime and Corporate Registries. "International Registries." Available online: https://www.register-iri.com/covid-19/\#implementation-of-imo (accessed on April 2021).

[16] Rocklöv, J, H Sjödin, and A Wilder-Smith. "COVID-19 Outbreak on the Diamond Princess Cruise Ship: Estimating the Epidemic Potential and Effectiveness of Public Health Countermeasures.” Journal of Travel Medicine 27, no. 3 (February 28, 2020). doi:10.1093/jtm/taaa030.

[17] Cheng, H.-Y., Li, S.-Y., \& Yang, C.-H. "Initial rapid and proactive response for the COVID-19 outbreak - Taiwan's experience." Journal of the Formosan Medical Association 119, no. 19 (April 2020): 771-773. doi:10.1016/j.jfma.2020.03.007.

[18] Lloyd's Register. (2021). Lloyd's Register Group Services Limited. Available online: https://www.lr.org/en/who-weare/coronavirus/ (accessed on March 2021).

[19] Japan - National Institute of Infectious Diseases. Available online: https://www.niid.go.jp/niid/en/2019-ncov-e/9407-covid-dpfe-01.html (accessed on March 2021).

[20] Choquet, Anne, and Awa Sam-Lefebvre. "Ports Closed to Cruise Ships in the Context of COVID-19: What Choices Are There for Coastal States?" Annals of Tourism Research 86 (January 2021): 103066. doi:10.1016/j.annals.2020.103066.

[21] Okeleke, U. J. “A Study of the Results of Coronavirus (COVID-19) on the Nigerian Maritime Workers” AIJR Reprints (August 10, 2020). doi:10.21467/preprints.176.

[22] Dahl, Eilif. "Coronavirus (Covid-19) Outbreak on the Cruise Ship Diamond Princess.” International Maritime Health 71, no. 1 (March 21, 2020): 5-8. doi:10.5603/mh.2020.0003.

[23] Vickerman, Roger. "Will Covid-19 Put the Public Back in Public Transport? A UK Perspective." Transport Policy 103 (March 2021): 95-102. doi:10.1016/j.tranpol.2021.01.005.

[24] Cosofret, Doru, and Elena-Rita Avram. "Evaluation of the Maritime Higher Education didactic support during the coronavirus pandemic. Case study.” The 15th International Conference on Virtual Learning ICVL. (2020): 493-499.

[25] Liberian Registry. "Liberian International Ship and Corporate Registry (LISCR).” Available online: https://seafarers.liscr.com/ (accessed on April 2021).

[26] Bureau Veritas. Available online: https://marine-offshore.bureauveritas.com/newsroom/covid-19-update-bureau-veritas-marineoffshore (accessed on April 2021).

[27] Stan, Liviu Constantin. “Online Teaching Technique in Maritime Learning Process.” Procedia - Social and Behavioral Sciences 116 (February 2014): 4517-4520. doi:10.1016/j.sbspro.2014.01.977.

[28] Republic of the Marshall Islands - Maritime Administrator. “International Registries.” Available online: https://www.registeriri.com/wp-content/uploads/MSA-2020-25.pdf (accessed on April 2021).

[29] United States Coast Guard. Available online: https://www.dco.uscg.mil/Portals/9/DCO\%20Documents/5p/MSIB/ 2020/MSIB\%2009-20\%20Vessel\%20Inspections_Exams_and_Documentation.pdf (accessed on March 2021).

[30] Panama Ship Registry. Available online: https://panamashipregistry.com/marine-notices/press-release-covid-19/ (accessed on April 2021).

[31] Tokyo MoU. Available online: http://www.tokyo-mou.org/doc/Press\%20Release\%20on\%20revision\%20of\%20Guidance\%20 relating\%20to\%20COVID-19.pdf (accessed on April 2021).

[32] Republic of the Marshall Islands - Maritime Administrator. "International Registries.” Available online: https://www.registeriri.com/wp-content/uploads/MSA-2020-24.pdf (accessed on April 2021).

[33] Republic of Cyprus. - Shipping Deputy Ministry. "Maritime Cyprus.” Available online: https://www.dms.gov.cy/dms/ shipping.nsf/all/A6AA0F6DBECA3CECC2258542003B5D55/\$file/Circular\%2009-2020\%20(2020-04-02).pdf?openelement (accessed on April 2021).

[34] International Association of Classification Societies (IACS). Available online: https://www.iacs.org.uk/media/6988/covid-19shipshorepersonnelinterfaceguidelines-6-may-2020.pdf (accessed on March 2021). 
[35] DNV GL. Available online: https://www.dnv.com/news/dnv-gl-maritime-response-to-the-coronavirus-covid-19-outbreak166449 (accessed on March 2021).

[36] The North of England Protecting and Indemnity Association Limited. (2021). North. Available online: https://www.nepia.com/publications/covid-19-coronavirus-outbreak-impact-on-shipping/ (accessed on March 2021).

[37] Liberian Registry. "Liberian International Ship and Corporate Registry (LISCR)." Available online: https://www.liscr.com/sites/default/files/liscr_press_releases/PR0120_Expedited\%20Registration\%20Process.pdf (accessed on January 2021).

[38] Republic of the Marshall Island - Maritime Administrator. "International Registries.” Available online: https://www.registeriri.com/wp-content/uploads/MG-1-04-1.pdf (accessed on April 2021).

[39] Republic of the Marshall Island - Maritime Administrator. "International Registries.” Available online: https://www.registeriri.com/wp-content/uploads/MN-1-004-3.pdf (accessed on April 2021).

[40] Daniil, Georgios, and Panagiotis Saviolakis. "Importance of Parallel - Bareboat Charter Registration and Its Connection with Marine Insurance." TransNav, the International Journal on Marine Navigation and Safety of Sea Transportation 14, no. 4 (2020): 953-960. doi:10.12716/1001.14.04.21.

[41] Michail, Nektarios A., and Kostis D. Melas. "Shipping Markets in Turmoil: An Analysis of the Covid-19 Outbreak and Its Implications." Transportation Research Interdisciplinary Perspectives $7 \quad$ (September 2020): 100178. doi:10.1016/j.trip.2020.100178.

[42] Miller, G. (2020, 04 27). Freightwaves. Available online: https://www.freightwaves.com/news/tanker-craziness-continues-asproduct-carriers-hit-record-high (accessed on April 2021). 